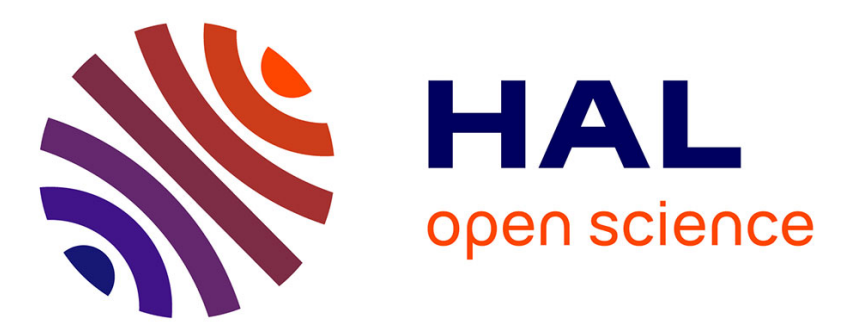

\title{
Efficacy of daptomycin combined with rifampicin for the treatment of experimental meticillin-resistant (MRSA) acute osteomyelitis
}

M. . Lefebvre, C. Jacqueline, G. Amador, V. Le Mabecque, A. Miegeville, G. Potel, J. Caillon, N. Asseray

\section{To cite this version:}

M. . Lefebvre, C. Jacqueline, G. Amador, V. Le Mabecque, A. Miegeville, et al.. Efficacy of daptomycin combined with rifampicin for the treatment of experimental meticillin-resistant (MRSA) acute osteomyelitis. International Journal of Antimicrobial Agents, 2010, 36 (6), pp.542. 10.1016/j.ijantimicag.2010.07.008 . hal-00640452

\section{HAL Id: hal-00640452 https://hal.science/hal-00640452}

Submitted on 12 Nov 2011

HAL is a multi-disciplinary open access archive for the deposit and dissemination of scientific research documents, whether they are published or not. The documents may come from teaching and research institutions in France or abroad, or from public or private research centers.
L'archive ouverte pluridisciplinaire HAL, est destinée au dépôt et à la diffusion de documents scientifiques de niveau recherche, publiés ou non, émanant des établissements d'enseignement et de recherche français ou étrangers, des laboratoires publics ou privés. 


\section{Accepted Manuscript}

Title: Efficacy of daptomycin combined with rifampicin for the treatment of experimental meticillin-resistant

Staphylococcus aureus (MRSA) acute osteomyelitis

Authors: M. Lefebvre, C. Jacqueline, G. Amador, V. Le

Mabecque, A. Miegeville, G. Potel, J. Caillon, N. Asseray

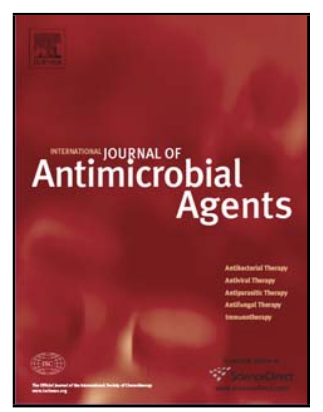

PII: S0924-8579(10)00335-3

DOI:

Reference: doi:10.1016/j.ijantimicag.2010.07.008

To appear in: International Journal of Antimicrobial Agents

Received date: $\quad$ 18-12-2009

Revised date: $\quad 27-6-2010$

Accepted date: $\quad 12-7-2010$

Please cite this article as: Lefebvre M, Jacqueline C, Amador G, Le Mabecque V, Miegeville A, Potel G, Caillon J, Asseray N, Efficacy of daptomycin combined with rifampicin for the treatment of experimental meticillin-resistant Staphylococcus aureus (MRSA) acute osteomyelitis, International Journal of Antimicrobial Agents (2010), doi:10.1016/j.ijantimicag.2010.07.008

This is a PDF file of an unedited manuscript that has been accepted for publication. As a service to our customers we are providing this early version of the manuscript. The manuscript will undergo copyediting, typesetting, and review of the resulting proof before it is published in its final form. Please note that during the production process errors may be discovered which could affect the content, and all legal disclaimers that apply to the journal pertain. 
Efficacy of daptomycin combined with rifampicin for the treatment of experimental meticillin-resistant Staphylococcus aureus (MRSA) acute osteomyelitis

M. Lefebvre, C. Jacqueline, G. Amador, V. Le Mabecque, A. Miegeville, G. Potel, J. Caillon, N. Asseray *

Université de Nantes, Faculté de Médecine, EA3826, 1 rue Gaston Veil, F-44035 Nantes, France

ARTICLE INFO

Article history:

Received 18 December 2009

Accepted 12 July 2010

Keywords:

MRSA

Daptomycin

Rifampicin

Osteomyelitis model

* Corresponding author. Tel.: +33 24041 2854; fax: +33 240412854.

E-mail address: nathalie.asseray@chu-nantes.fr (N. Asseray). 


\section{ABSTRACT}

Daptomycin exhibits rapid bactericidal activity against Gram-positive organisms, including meticillin-resistant Staphylococcus aureus (MRSA). Daptomycin in combination with rifampicin needs to be assessed in bone infection. An MRSA acute osteomyelitis model was used. Daptomycin and vancomycin were compared, alone or in combination with rifampicin, over 4 days. Surviving bacteria were counted in bone, bone marrow and joint fluid. Vancomycin and daptomycin as single therapies were ineffective, but both combinations were significantly more effective than the corresponding monotherapy. Combination of daptomycin and rifampicin could prevent $S$. aureus from developing resistance. This combination could be a useful alternative to treat MRSA osteomyelitis at an early stage. 


\section{Introduction}

Orthopaedic infections are among the most difficult to treat, involving surgical procedures and prolonged antibiotherapy [1]. Clinical guidelines are lacking in this area of infectious disease and most of the recommendations, such as the French recommendations [2], are simply based on expert opinion as there are insufficient data to support a high level of evidence. Glycopeptides remain the first-line recommended therapy for the treatment of meticillin-resistant Staphylococcus aureus (MRSA) orthopaedic infections, in combination with rifampicin when the microorganism is susceptible [3]. When MRSA is multiresistant, only a few therapeutic alternatives are available. Daptomycin is the first approved lipopeptide antibiotic and provides potent bactericidal activity against a broad range of Grampositive bacteria, including MRSA [4-6]. The relevance of its combination with rifampicin has recently been demonstrated in animal models, particularly in foreignbody infection models [7]. Daptomycin showed similar efficacy to vancomycin in previous experimental osteomyelitis studies but has not been evaluated at the early stage of treatment or in combination with rifampicin [8-10]. Therefore, this new antibiotic needs to be appraised in combination with rifampicin in an acute osteomyelitis model.

The present study aimed to assess the efficacy of daptomycin, compared with vancomycin, in combination with rifampicin in a rabbit model of experimental MRSA acute osteomyelitis. 


\section{Materials and methods}

\subsection{Bacterial strain}

MRSA strain BCB8 isolated from blood culture was used in the study.

\subsection{Antibiotics}

Daptomycin powder was supplied by Cubist Pharmaceuticals (Lexington, MA).

\subsection{Susceptibility testing}

Minimum inhibitory concentrations (MICs) of daptomycin, vancomycin and rifampicin were determined by the microdilution method in cation-adjusted Mueller-Hinton broth. For daptomycin, the test medium was supplemented with $50 \mathrm{mg} / \mathrm{L} \mathrm{Ca}^{2+}$ according to Clinical and Laboratory Standards Institute (CLSI) guidelines [11].

\subsection{Animals}

Study animals were female New Zealand White rabbits. This study was approved by the animal research committee of the University of Nantes (France). Fentanyl analgesia (fentanyl transdermal patch, $12 \mu \mathrm{g} / \mathrm{h}$ ) was used for pain management.

\subsubsection{Human pharmacokinetic simulation studies}

A first step in the pharmacokinetic studies consisted of investigating the parameters allowing simulation of the kinetics of daptomycin in human serum. Blood samples were taken from three healthy rabbits at $0,0.17,0.33,0.5,0.75,1,1.5,2,3,4,6,8$ 
and $24 \mathrm{~h}$ after administration of an intravenous (i.v.) bolus of daptomycin at $6 \mathrm{mg} / \mathrm{kg}$ body weight to determine spontaneous drug kinetics. Pharmacokinetic data were processed and were compared with those of humans [12]. A computer-controlled system was then used to obtain the human kinetic profiles for daptomycin in rabbits. Pharmacokinetic parameters were intended to simulate those observed in healthy volunteers following administration of $6 \mathrm{mg} / \mathrm{kg}$ i.v. daptomycin every $24 \mathrm{~h}$ [13]. The infusion was delivered by a computer-controlled pump that allowed the flow to be adjusted to a profile mathematically defined in time. To validate the simulation, plasma concentrations were determined in five rabbits.

Vancomycin was given as a continuous infusion at a dose of $100 \mathrm{mg} / \mathrm{kg}$ body weight/day so that the steady-state serum level was equivalent to the usual target in humans (ca. $25 \mathrm{mg} / \mathrm{L}$ ) [14]. Rifampicin $20 \mathrm{mg} / \mathrm{kg}$ was injected intramuscularly every $12 \mathrm{~h}$ to simulate human $10 \mathrm{mg} / \mathrm{kg}$ twice-daily oral administration [15].

\subsubsection{Osteomyelitis model}

The experimental procedure used in this work has been published recently [16]. A transarticular aperture was drilled in the cortical bone between the condyles on the right femur of the rabbits under general anaesthesia (ketamine $20 \mathrm{mg} / \mathrm{kg}$ i.v. and xylazine $1 \mathrm{mg} / \mathrm{kg}$ i.v.). An $8 \mathrm{G}$ needle was introduced into the medullary canal and was then removed. One millilitre of a bacterial suspension of MRSA adjusted to $10^{8}$ colony-forming units (CFU)/mL was injected into the knee cavity. Three days after inoculation, debridement and irrigation of the infected joint with $50 \mathrm{~mL}$ of sterile saline was performed. Samples of infected joint fluid, bone marrow and cortical bone were removed, weighed and homogenised in $500 \mu \mathrm{L}$ of sterile saline and then serial 
dilutions were plated on trypticase soy agar. Following overnight incubation at $37^{\circ} \mathrm{C}$, the number of viable bacteria was determined. After lavage and debridement, rabbits were randomly assigned to five regimens: no treatment (controls); monotherapy arms (daptomycin or vancomycin); and combination arms with rifampicin (daptomycin or vancomycin). For each group, eight animals were required to validate the results. At the end of a 4-day course of antibiotics, animals were euthanized and infected joint fluid, epiphyseal bone sample and femoral bone marrow were obtained. Dilutions at $10^{-1}, 10^{-2}$ and $10^{-4}$ were performed to avoid any carry-over effect. Bacterial counts were determined after $48 \mathrm{~h}$ of incubation at $37^{\circ} \mathrm{C}$. The efficacy measurement was performed by comparing the bacterial load before (Day 3 after infection) and after (Day 7 after infection) antibacterial therapy. The lower limit of detection was 20 $\mathrm{CFU} / \mathrm{mL}$. The endpoint was expressed as the mean difference \pm standard deviation in $\log \mathrm{CFU} / \mathrm{g}$ of infected tissue between Day 3 and Day 7 ( $\Delta \log \mathrm{CFU} / \mathrm{g})$.

\subsubsection{Emergence of resistance}

To determine whether antibiotic regimens could induce the selection of in vivo resistant variants, undiluted samples were spread on agar plates containing daptomycin or rifampicin at concentrations corresponding to $4 \times$ MIC. Bacteria recovered after $48 \mathrm{~h}$ of incubation at $37^{\circ} \mathrm{C}$ were tested to determine the MIC of daptomycin or rifampicin by the broth microdilution method.

\subsubsection{Histopathology}

Samples of the distal half of the femur bone were fixed in neutral-buffered formalin solution, dehydrated in a graded alcohol solution and embedded in methyl 
methacrylate. Longitudinal sections in a sagittal plane were cut at $5 \mathrm{~mm}$ and slices were stained with Masson-Goldner stain for histological analysis.

\subsection{Statistical analysis}

Mean loads from each group were compared by Newman-Keuls test after analysis of variance (ANOVA) using GraphPad Prism v4.0 (GraphPad Software Inc., San Diego, CA). A $P$-value $<0.05$ was considered significant.

\section{Results}

\subsection{Susceptibility testing}

MICs for MRSA strain BCB8 were $0.5 \mu \mathrm{g} / \mathrm{mL}$ for daptomycin, $1 \mu \mathrm{g} / \mathrm{mL}$ for vancomycin and $0.008 \mu \mathrm{g} / \mathrm{mL}$ for rifampicin.

\subsection{Pharmacokinetic data of daptomycin in serum}

Pharmacokinetic parameters of daptomycin obtained with the human-simulated dose of $6 \mathrm{mg} / \mathrm{kg}$ were close to those observed in humans: mean half-life $\left(T_{1 / 2}\right), 7.8 \pm 1.0 \mathrm{~h}$; peak concentration $\left(C_{\max }\right), 86.4 \pm 7.1 \mathrm{mg} / \mathrm{L}$; and area under the concentration-time curve (AUC), $705 \pm 67 \mathrm{mg} \mathrm{h} / \mathrm{L}$. 


\subsection{Osteomyelitis model}

All of the animals infected with MRSA exhibited positive joint fluid, bone marrow and bone smear cultures, with mean bacterial counts 3 days after infection of $7.7 \pm 0.4$, $7.9 \pm 0.3$ and $8.4 \pm 0.5 \log \mathrm{CFU} / \mathrm{g}$, respectively.

Following treatment, none of the animals in the daptomycin or vancomycin groups had sterile bone and the $\Delta \log$ CFU/g was not significantly different from that observed in the control group. In both antibiotic combination groups, the mean bacterial counts in the three osteoarticular samples were significantly lower than those in the control and in both monotherapy groups $(P<0.05)$. The combination of daptomycin plus rifampicin gave better results, with a greater reduction in the bacterial load (statistically significant only in the joint fluid, $P<0.01$ ) and a greater number of sterile bone samples (Table 1).

\subsection{Antibiotic resistance}

No variant resistant to rifampicin was detected in the group treated with daptomycin plus rifampicin, but resistant mutants were detected in one animal in the group treated with vancomycin plus rifampicin. The rifampicin MIC of mutants was $>32$ $\mathrm{mg} / \mathrm{L}$ compared with an initial MIC of $0.008 \mathrm{mg} / \mathrm{L}$. Resistant mutants to daptomycin were detected in five samples from three animals treated with daptomycin alone; the MICs of mutants were $2 \mathrm{mg} / \mathrm{L}$ and $4 \mathrm{mg} / \mathrm{L}$. 


\subsection{Histopathology}

In the inoculated femur, haematopoietic cells in the marrow spaces were preserved. Minimal to mild acute inflammation with intramedullary abscess was observed in the medulla of the metaphysis. Occasional bone necrosis was noticeable (data not shown).

\section{Discussion}

In this acute osteomyelitis model, daptomycin and vancomycin alone were ineffective at reducing the bacterial count significantly. Both combinations were more effective than the corresponding monotherapy. Bacterial eradication was achieved more often with the combination of daptomycin and rifampicin compared with and the combination of vancomycin and rifampicin. No emergence of resistance to rifampicin or daptomycin was observed in the daptomycin/rifampicin group, whereas resistance to daptomycin was detected in the monotherapy group.

Since daptomycin is used to treat infections caused by Gram-positive cocci resistant to $\beta$-lactams, its efficacy in the treatment of wound infections, especially in orthopaedic surgery, is of interest. This new antimicrobial could be a first step in the treatment of osteomyelitis and other orthopaedic infections. However, there are few data regarding its efficacy in treating such infections. Some experimental studies have compared daptomycin with vancomycin, showing a possible benefit of daptomycin $[8-10,17]$. The potential interest of daptomycin for the treatment of orthopaedic infections is supported by certain specific features of this antibiotic. Indeed, daptomycin has recently been shown to demonstrate activity against 
intracellular meticillin-susceptible $S$. aureus and MRSA in monocyte-derived macrophages, to inhibit slime synthesis and to induce slime disruption in vitro $[18,19]$. These properties could explain the potency of the association of daptomycin with rifampicin in such infections.

In this acute osteomyelitis model, no efficacy was achieved with either monotherapy regimen. Moreover, in another model, vancomycin and daptomycin monotherapy regimens were unable to cure any cage-associated infection [7]. In this model, daptomycin at high dose in combination with rifampicin showed the highest activity against planktonic and adherent MRSA.

The rabbit model used here was similar to human osteoarticular infection because of the mechanism of inoculation, the high bacterial load in bone without spontaneous cure, the combination of medical and surgical treatment, and the simulation of human pharmacokinetics. This acute osteomyelitis model is of interest in assessing efficacy of antibiotics at an early stage of treatment. The other models were different owing to a more moderate bacterial count in bone tissues leading to a spontaneous cure rate, or mimicking of haematogenous osteomyelitis $[8,20]$.

These results and recent literature highlight the importance of adding rifampicin to daptomycin in difficult-to-treat staphylococcal bone infections. This combination could be a promising and easier treatment option for orthopaedic infections caused by MRSA.

\section{Funding}


The study was funded by NOVARTIS.

\section{Competing interests}

None declared.

\section{Ethical approval}

In vivo studies were approved by the Animal Study Committee of the University of Nantes, France. 


\section{References}

[1] Lew DP, Waldvogel FA. Osteomyelitis. Lancet 2004;364:369-79.

[2] La Société de Pathologie Infectieuse de Langue Française (SPILF), et al. Clinical practice recommendations. Osteoarticular infections on materials (prosthesis, implant, osteosynthesis) [in French]. Med Mal Infect 2009;39:815-63.

[3] Zimmerli W, Trampuz A, Ochsner PE. Prosthetic-joint infections. N Engl J Med $2004 ; 351: 1645-54$.

[4] Critchley IA, Draghi DC, Sahm DF, Thornsberry C, Jones ME, Karlowsky JA. Activity of daptomycin against susceptible and multidrug-resistant Gram-positive pathogens collected in the SECURE study (Europe) during 2000-2001. J Antimicrob Chemother 2003;51:639-49.

[5] Sader HS, Streit JM, Fritsche TR, Jones RN. Antimicrobial susceptibility of Grampositive bacteria isolated from European medical centres: results of the Daptomycin Surveillance Programme (2002-2004). Clin Microbiol Infect $2006 ; 12: 844-52$.

[6] Wootton M, MacGowan AP, Walsh TR. Comparative bactericidal activities of daptomycin and vancomycin against glycopeptide-intermediate Staphylococcus aureus (GISA) and heterogeneous GISA isolates. Antimicrob Agents Chemother $2006 ; 50: 4195-7$.

[7] John AK, Baldoni D, Haschke M, Rentsch K, Schaerli P, Zimmerli W, et al. Efficacy of daptomycin in implant-associated infection due to methicillin-resistant Staphylococcus aureus: importance of combination with rifampin. Antimicrob Agents Chemother 2009;53:2719-24.

[8] Norden CW, Niederriter K. Treatment of experimental chronic osteomyelitis due to Staphylococcus aureus with LY146032. Infection 1988;16:27. 
[9] Mader JT, Adams K. Comparative evaluation of daptomycin (LY146032) and vancomycin in the treatment of experimental methicillin-resistant Staphylococcus aureus osteomyelitis in rabbits. Antimicrob Agents Chemother 1989;33:689-92.

[10] Luu QN, Buxton TB, Nelson DR, Rissing JP. Treatment of chronic experimental Staphylococcus aureus osteomyelitis with LY146032 and vancomycin. Eur J Clin Microbiol Infect Dis 1989;8:562-3.

[11] Clinical and Laboratory Standards Institute. Performance standards for antimicrobial susceptibility testing. Nineteenth informational supplement. Document M100-S19. Wayne, PA: CLSI; 2009.

[12] Bugnon D, Potel G, Caillon J, Baron D, Drugeon HB, Feigel P, et al. In vivo simulation of human pharmacokinetics in the rabbit. Bull Math Biol 1998;60:54567.

[13] Dvorchik BH, Brazier D, DeBruin MF, Arbeit RD. Daptomycin pharmacokinetics and safety following administration of escalating doses once daily to healthy subjects. Antimicrob Agents Chemother 2003;47:1318-23.

[14] Asseray N, Jacqueline C, Le Mabecque V, Batard E, Bugnon D, Potel G, et al. Activity of glycopeptides against Staphylococcus aureus infection in a rabbit endocarditis model: MICs do not predict in vivo efficacy. Antimicrob Agents Chemother 2005;49:857-9.

[15] Saleh-Mghir A, Ameur N, Muller-Serieys C, Ismael F, Lemaitre F, Massias L, et al. Combination of quinupristin-dalfopristin (Synercid) and rifampin is highly synergistic in experimental Staphylococcus aureus joint prosthesis infection. Antimicrob Agents Chemother 2002;46:1122-4.

[16] Amador G, Gautier H, Le Mabecque V, Miegeville AF, Potel G, Bouler JM, et al. In vivo assessment of the antimicrobial activity of a calcium-deficient apatite 
vancomycin drug delivery system in a methicillin-resistant Staphylococcus aureus rabbit osteomyelitis experimental model. Antimicrob Agents Chemother $2010 ; 54: 950-2$.

[17] Rose WE, Leonard SN, Rybak MJ. Evaluation of daptomycin pharmacodynamics and resistance at various dosage regimens against Staphylococcus aureus isolates with reduced susceptibilities to daptomycin in an in vitro pharmacodynamic model with simulated endocardial vegetations. Antimicrob Agents Chemother 2008;52:3061-7.

[18] Baltch AL, Ritz WJ, Bopp LH, Michelsen P, Smith RP. Activities of daptomycin and comparative antimicrobials, singly and in combination, against extracellular and intracellular Staphylococcus aureus and its stable small-colony variant in human monocyte-derived macrophages and in broth. Antimicrob Agents Chemother 2008;52:1829-33.

[19] Roveta S, Marchese A, Schito GC. Activity of daptomycin on biofilms produced on a plastic support by Staphylococcus spp. Int J Antimicrob Agents 2008;31:321-8.

[20] Yin LY, Lazzarini L, Li F, Stevens CM, Calhoun JH. Comparative evaluation of tigecycline and vancomycin, with and without rifampicin, in the treatment of methicillin-resistant Staphylococcus aureus experimental osteomyelitis in a rabbit model. J Antimicrob Chemother 2005;55:995-1002. 


\section{Table 1}

Bacterial counts in bone, bone marrow and joint fluid (difference between Day 7 and Day 3)

\begin{tabular}{llll}
\hline Treatment & \multicolumn{3}{l}{ Mean \pm S.D. $\Delta \log _{10}$ CFU/g of tissue (no. of sterile } \\
& \multicolumn{3}{l}{ samples/total no.) } \\
\cline { 2 - 4 } & Bone & Bone marrow & Joint fluid \\
\hline Control $(n=8)$ & $0.11 \pm 0.80(0 / 8)$ & $0.20 \pm 0.59(0 / 8)$ & $0.10 \pm 0.60(0 / 8)$ \\
Daptomycin $(n=8)$ & $-0.85 \pm 1.08(0 / 8)$ & $-0.69 \pm 0.67$ & $-1.06 \pm 0.99(0 / 8)$ \\
& & $(0 / 8)$ & \\
Vancomycin $(n=14)$ & $-0.75 \pm$ & $-0.61 \pm 1.50$ & $-0.72 \pm 1.39$ \\
& $0.81(0 / 14)$ & $(0 / 14)$ & $(0 / 14)$ \\
Daptomycin + rifampicin & $-4.51 \pm 0.81^{*, * *}$ & $-5.00 \pm 1.16^{*, * *}$ & $-4.568 \pm 1.32$ \\
$(n=9)$ & $(9 / 9)$ & $(8 / 9)$ & ${ }^{*, * *, \neq}(4 / 9)$ \\
Vancomycin + rifampicin & $-3.85 \pm 1.83^{*, * *}$ & $-4.24 \pm 1.98^{*, * *}$ & $-2.46 \pm 1.34^{*},{ }^{\dagger}$ \\
$(n=8)$ & $(1 / 8)$ & $(1 / 8)$ & $(1 / 8)$ \\
\hline
\end{tabular}

S.D., standard deviation; CFU, colony-forming units.

${ }^{*} P<0.01$ versus untreated controls.

${ }^{* *} P<0.001$ versus corresponding monotherapy.

${ }^{\dagger} P<0.05$ versus corresponding monotherapy.

$\ddagger P<0.01$ versus vancomycin + rifampicin. 